\title{
ARTIKELEN
}

\section{Wie B zei mag geen A zeggen}

\section{De kwestie van de switchende spermadonoren}

\author{
Mr. drs. S.E. Garvelink*
}

Op 1 juli 2004 trad de Wet donorgegevens kunstmatige bevruchting (Wdkb) in werking. Sindsdien is het niet meer mogelijk om anoniem sperma te doneren bij klinieken die kunstmatige donorbevruchting uitvoeren. Daarvoor kon dat wel en werd er een onderscheid gemaakt tussen $\mathrm{A}$-donoren $(\mathrm{A}=$ anoniem) en $\mathrm{B}$-donoren $(\mathrm{B}=\mathrm{bekend})$. Dit artikel gaat over de zogenoemde 'switchers'. Dat zijn donoren van vóór 2004 die bij donatie hadden verklaard er geen bezwaar tegen te hebben bekend te worden bij de met hun sperma verwekte kinderen, maar nu de kinderen oud genoeg zijn om de identificerende gegevens op te vragen (16 jaar of ouder) daar toch geen toestemming voor willen geven. Zij hebben een switch hebben gemaakt van B naar A. De Wdkb lijkt hun inderdaad het recht te geven om zo'n switch te maken, tot grote frustratie van alle betrokken kinderen en hun moeders. Er werd al geruime tijd reikhalzend uitgezien naar een oordeel van de rechter over deze kwestie. De rechtbank Gelderland ${ }^{1}$ en de rechtbank Den Haag ${ }^{2}$ hebben zich dit voorjaar kort na elkaar uitgesproken over 'switchers'. De uitkomsten zijn heel verschillend en dat vraagt om duiding.

\section{Het stelsel van de $\mathrm{Wdkb}$}

De Wdkb maakt een fundamenteel onderscheid tussen donoren die hebben gedoneerd na 1 juli 2004, de dag dat de Wdkb in werking trad, en de donoren die daarvoor al hadden gedoneerd. Voor de nieuwe donoren geldt de hoofdregel die staat in artikel 3 lid $2 \mathrm{Wdkb}$. Instellingen die kunstmatige bevruchting uitvoeren verzamelen de gegevens van de donor (naam, geboortedatum, woonplaats en eventueel ook contactgegevens) en geven die bij een doorgaande zwangerschap door aan de Stichting donorgegevens kunstmatige bevruchting (de Sdkb). Als een kind 16 jaar wordt, kan hij de Sdkb vragen om de persoonsidentificerende gegevens van de donor. De Sdkb verstrekt die gegevens, tenzij de donor bezwaar maakt en kan onderbouwen dat er zwaarwegende redenen zijn om dat niet te doen. De Sdkb maakt dan een belangenafweging om te beoordelen of belangen van de donor zwaarder wegen dan het belang van het kind om de identiteit van de donor wel te kennen. Deze procedure wordt beschreven in artikel 3 lid $2 \mathrm{Wdkb}$ en wordt verder uitge-

\footnotetext{
* Sebastiaan Garvelink is advocaat bij Van Benthem \& Keulen te Utrecht.

1 Rb. Gelderland 24 maart 2021, ECLI:NL:RBGEL:2021:1388. Zie ook: JIN 2021/81 m.nt. G.M.B.R. Niellissen.

2 Rb. Den Haag 2 juni 2021, ECLI:NL:RBDHA:2021:5461.
} 
werkt in het reglement van de $S d k b .{ }^{3}$ De $S d k b$ beoordeelde dit eerst helemaal zelf maar recent is een Adviescommissie in het leven geroepen die de Sdkb hierover moet adviseren. ${ }^{4}$ De donor, en naar mag worden aangenomen het kind als belanghebbende, kan tegen de beslissing van de $\mathrm{Sdkb}$ in beroep bij de bestuursrechter. Omdat het nu ruim 16 jaar geleden is dat de wet werd ingevoerd, is de verwachting dat de Sdkb de komende tijd veel aanvragen zal krijgen van kinderen die onder het regime van de Wdkb zijn verwekt.

Het probleem van het switchen doet zich voor bij de donoren van vóór 1 juli 2004. Die donoren hebben dikwijls anoniem gedoneerd. De gedachte van de wetgever was dat de $\mathrm{Wdkb}$ hun rechtspositie niet zomaar met terugwerkende kracht kon veranderen door hen te verplichten uit de anonimiteit te treden. Voor hen kwam er de overgangsregeling van artikel $12 \mathrm{Wdkb}$. Die houdt kort gezegd in dat donoren tot de inwerkingtreding konden aangeven of zij anoniem wilden zijn. In dat geval werden hun gegevens niet doorgegeven aan de Sdkb en werden zij dus verder met rust gelaten. Deze optie tot 'generieke weigering' staat in artikel 12 lid $2 \mathrm{Wdkb}$. Aan donoren die niet van deze mogelijkheid gebruik hadden gemaakt moet per geval om instemming worden gevraagd. De '[donor] gegevens (...) worden niet verstrekt (...) dan met instemming van de donor', zo bepaalt artikel 12 lid $3 \mathrm{Wdkb}$. De wet schrijft hier dus anders dan bij de donoren van na 1 juli 2004 geen belangenafweging voor. Hij kan weigeren zonder zwaarwegende redenen op te voeren.

Dit artikel 12 lid 3 Wdkb blijkt in de praktijk heel ongelukkig te kunnen uitpakken voor donorkinderen. De regeling maakt geen verschilt tussen A- en B-donoren. Dat betekent dat niet alleen donoren die destijds (voor 2004) als anonieme donoren hebben gedoneerd door de wet in de positie worden gebracht om hun instemming ongemotiveerd te weigeren, maar ook donoren die destijds als bekende donor hebben gedoneerd. Waar de wetgever juist ruimte wilden bieden aan de A-donoren om per 2004 vrijwillig een B-donor te worden, werd door het aanschrijven van de donoren in sommige gevallen het omgekeerde bereikt, een switch van B naar A. Dat dit leidt tot frustratie is goed te begrijpen. De moeders hadden bewust gekozen voor een B-donor om te voorkomen dat het kind met afstammingsvragen zou blijven zitten (bij alleenstaande moeders werd dat zelfs aanbevolen). De kinderen groeiden op met de verwachting dat deze informatie voor ze klaarlag.

Bij de tweede wetsevaluatie van de Wdkb hebben de evaluatoren de minister erop gewezen dat het hier wat hen betreft gaat om een weeffout in de overgangsregeling van artikel 12 $\mathrm{Wdkb} .{ }^{5}$ De minister heeft daarop geantwoord het probleem te zien en een wetswijziging te overwegen, maar eerst de uitspraken in twee lopende rechtszaken te willen afwachten. ${ }^{6}$

3 Het reglement is beschikbaar via de website van de Sdkb: www.donorgegevens.nl/documenten/wet-enregelgeving/2016/01/02/reglement-stichting-donorgegevens-kunstmatige-bevruchting. Zie ook: www.donorgegevens.nl/procedure-bij-zwaarwegende-belangen.

4 Besluit van de minister voor Rechtsbescherming en de minister van Volksgezondheid, Welzijn en Sport van 1 april 2021, kenmerk 220283-PG, houdende goedkeuring van het besluit tot wijziging van het Reglement Stichting donorgegevens kunstmatige bevruchting, Stcrt. 2021, 22793.

5 N.O.M. Woestenburg, B.J.M. Frederiks e.a., Tweede evaluatie Wdkb, Den Haag: ZonMW 2019, p. 12 en p. 163. Zie in dit tijdschrift ook: H.B. Winter, N.O.M. Woestenburg, J.H.H.M. Dorscheidt e.a., 'De Wet donorgegevens kunstmatige bevruchting geëvalueerd: nog steeds veel dorre grond', TvGR 2020, p. 5-18 en S.E. Garvelink en M.C. Ploem, ‘Tweede evaluatie Wdkb: stof tot nadenken’, TvGR 2020 p. 19-31.

6 Kamerstukken II 2019/20, 30486, nr. 24. 
Dat zijn de rechtszaken die hier worden besproken, zodat nu ook de vraag weer actueel is hoe de wetgever dit gaat opvolgen.

\section{Rechtbank Gelderland loopt tegen de grenzen van de wet aan}

In de Gelderse uitspraak van 24 maart $2021^{7}$ waren de feiten als volgt. Moeder had in 1997 een KID-behandeling ondergaan en daarbij bewust gekozen voor sperma van een B-donor, zodat haar kind de identiteit van de donor op enig moment zou kunnen kennen. Voorafgaand aan de inwerkingtreding van de Wdkb had het ziekenhuis echter een brief aan alle zaaddonoren gestuurd waarin hun werd gevraagd of zij met ingang van de nieuwe wet wilden blijven doneren als B-donor. De donor, aangeduid als 'K34' had daarop laten weten dat hij bij nader inzien toch een anonieme donor wilde zijn. Zijn status is daarop gewijzigd van B naar A. Wanneer dat precies gebeurd is, is niet helder, het ziekenhuis heeft dit achteraf gereconstrueerd. Toen de dochter voor het eerst om bekendmaking van de donor vroeg, bleek dat de donor een A van anoniem in zijn dossier had. Desgevraagd heeft de donor aan het ziekenhuis nog eens schriftelijk bevestigd dat hij niet wilde dat zijn identiteit bekend werd gemaakt. Aan het FIOM, dat probeerde te bemiddelen, gaf hij als reden dat zijn huidige vrouw niet openstaat voor contact tussen hem en zijn afstammelingen. Het ziekenhuis heeft de gegevens van K34 wel doorgegeven aan de Sdkb, maar omdat toestemming ontbreekt achtte naast het ziekenhuis ook de Sdkb zich niet langer vrij om de gegevens te verstrekken. De dochter en haar moeder begonnen daarop een procedure tegen het ziekenhuis om dat af te dwingen.

De rechtbank Gelderland ziet een conflict van plichten, waarin zowel de dochter als de donor zwaarwegende belangen hebben. Enerzijds staat vast dat het ziekenhuis op basis van de geneeskundige behandelingsovereenkomst ('de inseminatieovereenkomst') met de moeder de persoonsgegevens van K34 in beginsel zou moeten verstrekken. Moeder meende immers met een B-donor te maken te hebben. Bovendien heeft de dochter op grond van artikel 7 lid 1 IVRK en artikel 8 EVRM het recht om haar ouders te kennen en - nu zij onder de situatie lijdt - een zwaarwegend recht om dat te effectueren. Anderzijds heeft het ziekenhuis ook een zwaarwegende verplichting om de wens van de donor tot geheimhouding te respecteren. Die volgt uit het beroepsgeheim van artikel 7:457 BW en uit artikel 8 EVRM. Saillant detail is nog dat K34 een donor is met wiens donorzaad meer kinderen zijn verwekt dan op grond van de richtlijnen is toegestaan, hierover is ook een procedure geweest. ${ }^{8}$ De rechtbank zinspeelt er in r.o. 4.13 op dat dit ook wel een rol zou kunnen spelen bij zijn weigerachtige houding. Hoe dit ook zij: nu het ziekenhuis zowel jegens moeder en dochter als jegens de donor conflicterende plichten heeft, beroept het zich op overmacht. Zo'n tegenstelling vraagt om een zorgvuldige belangenafweging.

Interessant is hoe de rechtbank Gelderland vervolgens omgaat met artikel 12 lid $3 \mathrm{Wdkb}$, dat immers een belangenafweging bij een donor van voor 1 juli 2004 lijkt uit te sluiten, zoals ook het ziekenhuis heeft aangevoerd. De rechtbank stelt vast dat artikel 12 lid 3 ook

7 Rb. Gelderland 24 maart 2021, ECLI:NL:RBGEL:2021:1388. Zie voetnoot 1.

8 Rb. Gelderland 12 juni 2017, ECLI:NL:RBGEL:2017:3083, zie 'Uitspraken over spermadonoren, m.nt. mr. drs. S.E. Garvelink', TvGR 2017, p. 584-600. 
het ziekenhuis bindt, ook al richt de norm zich formeel tot de Sdkb. Eiseressen hebben dit niet betwist en het zou artikel 12 lid 3 wel heel makkelijk omzeilbaar maken als de gegevens die de Sdkb niet kan delen bij de instelling kunnen worden opgevraagd. De rechtbank zegt dat een direct beroep op artikel 7 lid 1 IVRK niet mogelijk is, omdat die norm zich richt tot de overheid. Het toetsingsverbod van artikel $120 \mathrm{GW}$ staat eraan in de weg om te beoordelen of artikel 12 lid $3 \mathrm{Wdkb}$ al dan niet in strijd is met artikel 7 lid 1 IVRK of met algemene rechtsbeginselen en (ander) ongeschreven recht (de rechtbank Den Haag ziet dat anders, zie hierna). Een door de Hoge Raad erkende optie is dan nog dat een beroep op dit artikel naar maatstaven van redelijkheid en billijkheid onaanvaardbaar is, omdat sprake is van niet-verdisconteerde bijzondere omstandigheden. Dat is hier het geval. De rechtbank noemt een aantal omstandigheden. Iedereen heeft in beginsel recht om zijn afstamming te kennen. Kinderen die afstammen van B-donoren mochten erop rekenen dat zij de identiteit van de donor te weten zouden komen. Er is geen reden te bedenken waarom kinderen van voor 2004 geen belangenafweging krijgen en kinderen van daarna wel. Tot slot heeft de minister in zijn brief naar aanleiding van de wetsevaluatie erkend dat de situatie van de switchers niet is verdisconteerd. Dat alles maakt dat het ziekenhuis zich hier niet op artikel 12 lid $3 \mathrm{Wdkb}$ kan beroepen.

Daar schieten eiseressen hier echter niets mee op. De rechtbank wijst hun vorderingen af. Er moet een belangenafweging gemaakt worden, maar de rechtbank kan die niet maken omdat K34 geen partij is in de procedure. Het procesrecht biedt geen mogelijkheden om dit te repareren. De rechtbank verwerpt ook het voorstel om de belangenafweging dan maar door een onafhankelijke deskundige te laten uitvoeren. K34 is niet verplicht daaraan mee te werken. Bovendien kan K34 als niet-partij ook niet in beroep als het vonnis in zijn nadeel uitpakt. De toegang van K34 zou daarmee op onaanvaardbare wijze worden beperkt. De rechtbank wil wel belangen afwegen, maar loopt aan tegen de beperkingen van het procesrecht. Een 'onbevredigende slotsom', aldus de rechtbank, en 'de wetgever is aan zet'. Eiseressen worden naar huis gestuurd met een proceskostenveroordeling en het soort paradox dat alleen voor liefhebbers van formele logica leuk is: om de donor te kennen moeten zij hem dagvaarden, alleen kunnen zij hem niet dagvaarden, omdat zij hem niet kennen. Sinds het verschijnen van de fameuze oorlogsroman Catch-22 van Joseph Heller noemen we dat soort paradoxen een 'catch-22' naar de vliegenier die in dat boek alleen onder een zelfmoordmissie kan uitkomen door zich krankzinnig te laten verklaren, maar door dat te proberen voor de keuringsarts aantoont dat hij juist niet krankzinnig is. De cirkel kan afgaand op deze uitspraak alleen worden doorbroken als de wetgever bepaalt dat voor de B-donoren ook het regime van artikel 3 lid $2 \mathrm{Wdkb}$ gaat gelden.

\section{Rechtbank Den Haag schuift de wet opzij}

De uitspraak van de rechtbank Den Haag van 2 juni $2020^{9}$ gaat uit van feiten die erg lijken op de zaak voor de rechtbank Gelderland, maar kent een heel andere uitkomst. Ook hier gaat het om donorkinderen en hun moeders die de identiteit van een switcher willen weten, hier niet 'K34' geheten maar 'Donor 605'. De behandelingen hebben ook hier voor 
de invoering van de Wdkb plaatsgevonden met sperma van een B-donor. Donor 605 is in 1997 een donorovereenkomst aangegaan waarbij hij op een formulier het vakje B-donor heeft aangevinkt. Relevant is dat op dat formulier wordt toegelicht wat het inhoudt Bdonor te zijn: 'van deze donors mag de identiteit op verzoek van het kind, als het 16 jaar of ouder is, bekend gemaakt worden. De [instelling] zal als haar zo'n verzoek bereikt bij de donor nagaan of er zwaarwegende redenen zijn ontstaan om alsnog af te zien van het opheffen van de anonimiteit'. ${ }^{10}$ Toen de donorkinderen de leeftijd van 16 jaar hadden bereikt hebben zij eerst de Sdkb gevraagd om de donorgegevens van Donor 605 aan hen te verstrekken. De Sdkb heeft daarop Donor 605 per brief benaderd met een antwoordformulier waarop hij kon aankruisen of hij daarmee wel of niet instemde. Hij heeft steeds zonder toelichting aangekruist dat hij niet instemt en dit is door de Sdkb aan eisers meegedeeld. Eisers hebben vervolgens ook de instelling verzocht om de gegevens van Donor 605 te verstrekken, waarop de instelling antwoordde dat zij dat niet kon doen omdat niet zij maar de Sdkb de aangewezen partij was om zo'n verzoek te behandelen. Hierop hebben eisers zowel de Sdkb als de instelling gedagvaard. Hangende de procedure hebben de instelling en de Sdkb nog een keer geprobeerd met Donor 605 in gesprek te komen, maar op die uitnodiging is hij niet ingegaan.

Het verweer van de Sdkb is dat zij bij donoren van voor 1 juli 2004 nu eenmaal het regime van artikel 12 lid $3 \mathrm{Wdkb}$ moet toepassen: niet verstrekken, tenzij er toestemming is. Dat verweer slaagt niet. De Haagse rechtbank stelt artikel 12 lid 3 Wdkb buiten werking op grond van artikel 94 Grondwet, het artikel dat de rechter de bevoegdheid geeft om wettelijke voorschriften te toetsen aan ieder verbindende verdragsbepalingen. Dat gaat in drie stappen. De eerste stap is de vaststelling dat artikel 7 lid 1 IVRK (het recht van ieder kind om de ouders te kennen) en artikel 8 lid 1 EVRM (recht op gezinsleven) voldoende concreet zijn om te kunnen gelden als ieder verbindende verdragsbepaling. De tweede stap is de vaststelling dat artikel 12 lid 3 onverenigbaar is met die bepalingen. Door toepassing van artikel 12 lid 3 wordt geen recht gedaan aan het feit dat Donor 605 als bekende donor heeft te gelden jegens de met zijn zaad verwekte kinderen. Tot de inwerkingtreding van de Wdkb waren de afspraken met de kliniek bepalend voor de anonimiteit. De wetgever heeft willen waarborgen dat die donoren die onder de voorwaarde van anonimiteit doneerden hun anonimiteit konden behouden. Bij donoren die destijds helemaal geen anonimiteit hebben afgesproken is 'van behouden van anonimiteit' geen sprake. De derde stap is ten slotte de beantwoording van de vraag wat er dan wel geldt als artikel 12 lid 3 hier komt te vervallen. Dat antwoord is eenvoudig. Als de overgangsregeling niet geldt, dan geldt dus de hoofdregel van artikel 3 lid $2 \mathrm{Wdkb}$ : verstrekking tenzij (voldoende) zwaarwegende belangen zich daartegen verzetten.

De instelling heeft geprobeerd zich te verweren door eisers te verwijzen naar de Sdkb, maar dat verweer kan de instelling niet baten. De instelling heeft zelf afspraken gemaakt met de moeders ter zake van het gebruik van sperma met een B-donor, die de instelling moet nakomen. Uit niets blijkt dat de wetgever de $\mathrm{Wdkb}$ in de plaats wilde stellen van dergelijke private afspraken. Dat het in casu niet redelijk zou zijn om de instelling aan die afspraken te houden ziet de rechtbank niet. De instelling stelt dat de Sdkb beter toegerust is 
om een goede belangenafweging te maken, maar dat argument overtuigt niet omdat het de instelling er destijds niet van heeft weerhouden zo'n belangenafweging onderdeel te maken van de afspraken met de donor en de moeders. Een beroep op het beroepsgeheim slaagt ook niet, want de donor heeft de instelling bij het aangaan van de donatieovereenkomst toestemming gegeven om zijn gegevens te zijner tijd aan donorkinderen te verstrekken. Het laatste argument van de instelling is dat de donor tegen een beslissing van de instelling niet in bezwaar kan. Bij de Sdkb kan dat wel en dus zouden zijn rechten beter geborgd zijn als de Sdkb over verstrekking beslist. Ook dat ziet de rechter niet. Als de instelling tot de conclusie komt dat zij tot verstrekking mag overgaan omdat er geen belangen zijn die verstrekking in de weg staan, kan zij Donor 605 eerst nog een termijn gunnen om dat door middel van een civiele procedure tegen te houden.

De donorkinderen en hun moeders hebben in Den Haag dubbel succes. De Sdkb wordt ertoe veroordeeld de procedure van artikel 3 lid 2 e.v. te volgen, wat ertoe zal leiden dat als er geen zwaarwegende belangen zijn, de Sdkb de gegevens verstrekt. Gelijktijdig wordt de instelling ertoe veroordeeld om de identiteit van de donor binnen vier maanden bekend te maken, tenzij er zwaarwegende belangen zijn die zich daartegen verzetten. Bij beide routes moet er eerst nog een belangenafweging plaatsvinden. De stelling van eisers dat Donor 605 de gelegenheid om zwaarwegende belangen aan te voeren al heeft gehad wordt door de rechtbank verworpen. Naar ik meen terecht, omdat hem bij de keren dat hij door de Sdkb of de instelling is benaderd blijkbaar steeds is voorgehouden dat hij conform artikel 12 lid $3 \mathrm{Wdkb}$ ongemotiveerd mocht weigeren, wat nu dus niet blijkt te kloppen.

\section{Vergelijking van de twee uitspraken}

Verschil 1: Belang en rechtsbescherming van de donor

Een verschil in de feiten is dat de donatieafspraak met de donor in de Haagse casus wat beter gedocumenteerd was dan de afspraak met de donor in de Gelderse casus. Op het formulier dat Donor 605 had ondertekend stond immers met zoveel woorden vermeld dat de instelling bij keuze voor B-donorschap zou nagaan of er zwaarwegende redenen waren om de gegevens niet te verstrekken. Daarmee was die afspraak met Donor 605 in zekere zin een voorafschaduwing van het regime van artikel 3 lid $2 \mathrm{Wdkb}$ en kon zich minder snel een conflict van plichten voordoen. Aan de Gelderse donor K34 is niet zo duidelijk voorgehouden dat hem een belangenafweging te wachten stond als hij bij nader inzien niet zou instemmen met verstrekking van zijn gegevens. Dit blijkt althans niet uit de stukken die de rechtbank Gelderland in het vonnis citeert. Dat verschil lijkt mij niet echt wezenlijk. Ook voor K34 staat vast dat hij ooit is begonnen als B-donor. Toen moet hem duidelijk geweest zijn wat dat inhield. Ook de rechtbank Gelderland zelf vindt een beroep van het ziekenhuis op artikel 12 lid $3 \mathrm{Wdkb}$ hier niet redelijk en billijk. Dan lijkt het wel zo logisch om het ziekenhuis dan dus ook het regime van artikel 3 lid $2 \mathrm{Wdkb}$ te laten toepassen. Wie A zegt moet ook B zeggen (no pun intended).

Opvallend is dat de rechtbank Gelderland hierbij een cruciaal punt maakt van het feit dat de donor geen partij is bij de procedure en zijn belangen niet kan toelichten, terwijl de rechtbank Den Haag daarin geen probleem ziet. Net als de Sdkb moet van de rechtbank ook de instelling de belangen afwegen. Als de donor het niet met de uitkomst eens is, moet 
hij maar een civiele procedure starten. Zo is zijn rechtsbescherming toch gewaarborgd. Deze lijn van de rechtbank Den Haag lijkt mij verdedigbaar, omdat anders de eisende partij in een onmogelijke procespositie wordt gebracht (zie hiervoor, 'catch-22'), terwijl de donor bij toepassing van artikel 3 lid $2 \mathrm{Wdkb}$ zijn belangenafweging alsnog krijgt. Nu zowel de $\mathrm{Sdkb}$ als de instelling parallel de opdracht krijgen een belangenafweging te maken, creëert de rechtbank Den Haag wel de mogelijkheid dat zij tot een andere afweging komen. ${ }^{11}$

Verschil 2: Sdkb wel/geen procespartij.

Een ander evident verschil is dat in de procedure in Gelderland de Sdkb geen gedaagde was en in Den Haag wel, waarbij de vordering tegen de Sdkb in Den Haag ook inderdaad slaagt. De Sdkb is een bestuursorgaan met een publiekrechtelijke taak. De Sdkb valt al sinds 2014 onder de Kaderwet zbo's. De rechtsvorm is op dit moment nog privaatrechtelijk, maar dat zal in de toekomst veranderen. ${ }^{12}$ Dit werpt de vraag op of een weigering van de Sdkb om de gegevens aan een donorkind te verstrekken niet eigenlijk een appellabel besluit is in de zin van artikel 1:3 Awb. Dat had er in het uiterste geval toe kunnen leiden dat de civiele rechter de donorkinderen en hun moeders niet-ontvankelijk had verklaard, indien deze zou hebben gemeend dat er een met voldoende waarborgen omklede bestuurlijke rechtsgang openstond (of had gestaan) waarmee zij hetzelfde konden bereiken. In de procedure bij de rechtbank Den Haag, waar de Sdkb dus wel gedaagde was, is dit echter blijkbaar geen punt van discussie geweest. Hoe de rechtbank Gelderland een civiele vordering tegen de Sdkb zou hebben beoordeeld is niet bekend. Het is echter zeer wel denkbaar dat die vordering net als de vordering tegen het Gelderse ziekenhuis stukgelopen was op het feit dat de donor geen procespartij was en hij zijn belangen niet kon toelichten.

\section{Verschil 3: toets aan hoger recht}

Zeker is dat de publiekrechtelijke rol en positie van de Sdkb in de Haagse casus relevant zijn voor het slagen van een beroep op artikel 7 lid 1 IVRK jo. artikel 94 GW. Het VN-Kinderverdrag bevat normen die zich richten tot de overheid. Welnu: de Sdkb is wel beschouwd de overheid en het IVRK heeft in de verhouding burger-overheid rechtstreekse werking, zo weten we ook uit het vreemdelingenrecht. ${ }^{13}$ Daarbij kan worden opgemerkt dat artikel $94 \mathrm{GW}$ niet alleen geldt voor de rechter, maar voor de hele overheid. De Sdkb kan dus geen bepalingen uit de Wdkb toepassen (hier dus artikel 12 lid 3) als dat in strijd is met ieder verbindende verdragsbepalingen. Artikel 7 lid 1 IVRK wordt in beide uitspraken

11 Wat de beweegredenen van Donor 605 in de Haagse casus zijn en wat hij zal gaan aanvoeren als zwaarwegende reden is niet bekend. Uit de Gelderse casus blijkt wel iets van de mogelijke belangen van K34: hij heeft aan het FIOM verteld dat zijn vrouw er niet voor openstaat als hij contact heeft met zijn donorkinderen. Dat lijkt vooralsnog niet erg sterk. K34 is namelijk niet verplicht zijn nakomelingen te ontmoeten (en zijn vrouw al helemaal niet). Dat het ziekenhuis met het sperma van K34 meer dan de toegestane 25 nakomelingen heeft verwekt is slordig van het ziekenhuis, maar de vraag is of dat een zwaarwegende reden is om anoniem te willen blijven. Hoe dit ook zij: bij de huidige stand van zaken hoeft $\mathrm{K} 34$ zich niet te verantwoorden en Donor 605 wel.

12 Op grond van de aankomende wetswijziging van de Wdkb zal de privaatrechtelijke rechtsvorm worden omgezet in een bestuursrechtelijke rechtsvorm, zie paragraaf 6 van dit artikel. Feitelijk is het echter nu al zo dat het beleid over de uitvoering van de Wdkb geheel bij de minister van VWS is belegd, zodat van een wezenlijke wijziging in de praktijk geen sprake is. Zie Kamerstukken II 2021/22, 35870, 3, p. 3 en p. 25 e.v. 
aangehaald om het belang van het kind bij afstammingsinformatie te onderstrepen en de context van de Wdkb te schetsen. Uit deze uitspraken blijkt niet dat het IVRK ook rechtstreeks en horizontaal werkt in de verhouding tussen private partijen, dus in de verhouding tussen enerzijds moeder en kind en anderzijds het ziekenhuis. De rechtbank Gelderland zegt van niet omdat de normadressaat van het IVRK de overheid is. ${ }^{14}$ Daarbij begrijp ik niet helemaal waarom de rechtbank Gelderland wel verwijst naar het toetsingsverbod van artikel $120 \mathrm{GW}$, maar helemaal niet naar het toetsingsgebod van artikel $94 \mathrm{GW}$. Dat is hier het relevante kader, want eiseressen beroepen zich niet op de grondwet maar op het IVRK. De rechtbank Den Haag komt bij het bepalen van de verplichtingen van de instelling jegens eisers niet toe aan de beoordeling van een eventuele rechtstreekse en horizontale werking van het IVRK. Voor een veroordeling van de instelling tot verstrekking van de gegevens heeft de rechtbank genoeg heeft aan de privaatrechtelijke afspraken die de instelling heeft gemaakt met de donoren en de moeders. ${ }^{15}$

\section{Wetgever of rechter?}

Welke uitspraak is nu beter? Dat is lastig, want zoals zojuist besproken kregen de twee rechtbanken niet exact dezelfde casus op dezelfde manier gepresenteerd. Toch heeft de Haagse uitspraak meer potentieel om school te maken. De rechter lost het op en legt de verantwoordelijkheid niet terug bij de wetgever. Op sociale media kwam de typering 'moedig' voorbij. De uitspraak in Gelderland is - vindt de rechtbank zelf ook - 'onbevredigend'. Inmiddels is bekend dat de Haagse uitspraak ook in Gelderland voor een bevredigend einde lijkt te gaan zorgen. Vlak voordat deze aflevering van het Tijdschrift voor Gezondheidsrecht naar de drukker ging, berichtte de Volkskrant dat de Sdkb naar aanleiding van de Haagse uitspraak een koerswijziging zal doorvoeren. Dat betekent dat de Sdkb ten behoeve van het donorkind dat van K34 afstamt alsnog een belangenafweging zal uitvoeren en dat ook in de toekomst zal doen voor andere kinderen van switchers. ${ }^{16}$ Als bij die belangenafweging geen heel bijzondere belangen van de donor aan het licht komen, dan worden de gegevens van K34 gedeeld.

Een uitkomst waarbij het kind hoort wie zijn vader is, appelleert aan gevoelens van rechtvaardigheid en brengt 'closure' en catharsis, zowel voor de direct betrokkene als de toeschouwer. Het is natuurlijk de vraag of dat altijd de taak is van het recht. Die vraag raakt aan de aloude tegenstelling tussen rechtspositivisme en natuurrecht. Rechtstheoretisch past de uitspraak van de rechtbank Gelderland meer in de school van de rechtsfilosoof H.L.A. Hart. ${ }^{17}$ De uitspraak van de rechtbank Den Haag past meer bij de denkbeelden van R. Dworkin. ${ }^{18}$ Voor Hart bestaat recht uit de wetten die in het parlement tot stand zijn gekomen. Dat dient de rechtszekerheid. Moed is voor rechters niet per se een deugd. Voor Dworkin is de term recht geladen met een notie van rechtvaardigheid en is er meer ruimte

14 Rb. Gelderland, r.o. 4.8.

15 Rb. Den Haag, r.o. 5.48.

16 P. De Lange, 'Na een koerswijziging bij Stichting Donorgegevens mag Maria eindelijk weten wie haar vader is', de Volkskrant 9 november 2021.

17 Zie zijn hoofdwerk The Concept of Law, voor het eerst verschenen in 1961.

18 Zie met name Taking Rights Seriously (1977) en Law's empire (1986). 
voor een teleologische uitleg, waarbij de oplossing wordt gevonden in hogere rechtsprincipes.

Ik kan hier wel leven met die tweede aanpak. Omdat B-donoren zelf bekendheid hadden beloofd en de moeders onder die premisse kozen voor hun sperma, gaat het niet aan om een switch wettelijk te beschermen. De Haagse rechter laat zien dat dit vraagstuk ook zonder wetswijziging kan worden opgelost. Zoals gezegd is de Sdkb volgens de laatste berichten inmiddels ook 'om' en heeft zij een koerswijziging aangekondigd. Toch is regeling bij formele wet nog steeds noodzakelijk, al was het maar omdat de rechter heeft vastgesteld dat de wet in strijd is met internationale verdragen. Een wetswijziging biedt ook meer rechtszekerheid aan donorkinderen, ouders en donoren dan alleen een vonnis van een lagere rechter. Verder kan de Sdkb ondanks haar nieuwe welwillende beleid in sommige gevallen de gegevens niet verstrekken, omdat de instelling ze niet altijd heeft doorgegeven.

\section{Aanstaande wetswijziging}

Op 23 juni 2021 is een wetsvoorstel tot wijziging van de Wdkb ingediend bij de Tweede Kamer. ${ }^{19}$ Dit voorstel volgt een aantal van de aanbevelingen uit de tweede wetsevaluatie en regelt de omvorming van de Sdkb naar een publiekrechtelijk bestuursorgaan dat voluit 'College donorgegevens kunstmatige bevruchting' (Cdkb) zal gaan heten. Hierin zal onder meer ook een donorkind zitting nemen. Het voorstel bevat echter nog geen regeling voor het probleem van de switchers. De minister noemt het probleem in de memorie van toelichting en het advies van de Raad van State al wel. In de besproken gerechtelijke uitspraken ziet hij aanleiding om een (nadere) wetswijziging te initiëren. Mogelijk zal dit geschieden in de vorm van een nota van wijziging op het nu voorliggende voorstel, maar dit vergt nog 'de nodige bestudering en afstemming' ${ }^{20}$

Hoe de wetstekst er concreet zal gaan uitzien is nu dus nog niet bekend, maar de strekking zal wel zijn dat de switchers onder het regime van het huidige artikel 3 lid $2 \mathrm{Wdkb}$ worden gebracht: hun gegevens worden verstrekt, behoudens in geval van zwaarwegende belangen. Voor die gevallen waarin de instelling de donorgegevens nooit heeft doorgegeven aan de Sdkb zou de wet duidelijk(er) moeten stellen dat dit alsnog moet gebeuren, zodat de $\mathrm{Sdkb}$ de belangenafweging kan uitvoeren. Het is daarbij natuurlijk nog steeds mogelijk dat de belangenafweging in het voordeel van de weigerachtige donor uitvalt en de gegevens niet worden verstrekt. Dat lijkt vooral een theoretische mogelijkheid. Bij de belangenafweging legt het belang van het kind om zijn afstammingsgegevens te kennen erg veel gewicht in de schaal. Uit de parlementaire geschiedenis bij artikel 3 lid $2 \mathrm{Wdkb}$ blijkt dat de wetgever geen zeer overtuigende voorbeelden kon bedenken van redenen om het kind de donorgegevens te onthouden. De wetsgeschiedenis noemt de situatie dat de donor in de gevangenis zit of in een zodanige psychische toestand verkeert dat het niet verantwoord is zijn

19 Wijziging van de Wet donorgegevens kunstmatige bevruchting in verband met de tweede evaluatie van de wet, het actieplan ter ondersteuning van donorkinderen en de omvorming van de Stichting donorgegevens kunstmatige bevruchting tot publiekrechtelijk zelfstandig bestuursorgaan ingediend bij de Tweede Kamer (Kamerstukken II 2020/21, 35870, nr. 2 en 3).

20 Kamerstukken II 2020/21, 35870, nr. 4, p. 6. Zie ook Kamerstukken II 2020/21, 35870, nr. 27. 
identiteit bekend te maken. ${ }^{21}$ Volgens de minister zal het uitzonderlijk zijn dat de Sdkb (straks dus het $\mathrm{Cdkb}$ ) na een belangenafweging niet overgaat tot verstrekking. ${ }^{22}$ De Sdkb heeft op dit punt nog weinig precedenten ontwikkeld, dat is een taak voor de nieuwe Adviescommissie.

Als de Stichting straks wordt omgevormd tot College kan men om het publiek- en bestuursrechtelijke kader van zijn besluiten niet langer heen. Toch lijkt het mij zinvol om in artikel $3 \mathrm{Wdkb}$ of ten minste in het reglement te expliciteren dat bij een bezwaar van de donor het kind als belanghebbende door de Adviescommissie moet worden gehoord. Dat lijkt evident op grond van artikel 1:2 Awb, maar het staat nog niet in de wet of het wetsvoorstel of het meest recente reglement van de Sdkb. Als het kind vervolgens zijn of haar verzoek niet gehonoreerd ziet worden, kan het doorprocederen tot aan de Raad van State.

\section{Het belang van het kind voorop}

Sinds de jaren negentig van de vorige eeuw is het recht van het kind om zijn of haar (biologische) ouders te kennen onmiskenbaar aan een opmars bezig binnen de grondrechtenhiërarchie. Daaraan heeft behalve het IVRK ook de rechtspraak van het EHRM bijgedragen. ${ }^{23}$ In die opmars past ook de invoering van de Wdkb zelf. Ten behoeve van het kind is het anonieme donorschap opgeheven, al hield men er rekening mee dat er daardoor minder makkelijk donoren gevonden konden worden en dat het dus voor sommige stellen en alleenstaande vrouwen moeilijker zou worden om hun kinderwens in vervulling te laten gaan. De belangen van de wensouders worden weliswaar ook beschermd door het recht op gezinsleven in artikel 8 EVRM, maar het recht van het kind op afstammingsgegevens heeft prioriteit.

Het belang van dit recht wordt door beide hier besproken uitspraken onderstreept.

Zet deze trend nog verder door, dan zou op zeker moment zelfs de anonimiteit van de Adonoren van vóór 1 juli 2004 onder druk kunnen komen te staan. In de tweede wetsevaluatie van de Wdkb wordt al bepleit om te kijken of die anonimiteit geheel kan worden opgeheven. ${ }^{24}$ De gedachte is dat afspraken van een instelling met de donor over anoniem doneren ook voor 1 juli 2004 al onrechtmatig kunnen zijn jegens het (nog ongeboren) donorkind, omdat daarmee het in artikel 7 lid 1 IVRK vastgelegde recht onevenredig wordt belemmerd. Ik ben daar geen voorstander van. Het komt mij voor dat de positie van de consequente A-donoren nog altijd een heel andere is dan die van de geswitchte B-donoren.

21 Kamerstukken I 2000/01, 23207, nr. 201b, p. 3.

22 Kamerstukken II 2019/20, 30486, nr. 24, p. 6.

23 Voor een meer uitgebreide schets van de Europese rechtspraak en dogmatische achtergronden zie de annotatie van Niellissen bij de Gelderse uitspraak in JIN 2021/81 (zie voetnoot 1). Zie ook mijn voetnoot bij Rb. Rotterdam 2 juni 2017, ECLI:NL:RBROT:2017:4250, TvGR 2017, p. 584-600.

24 Zie N.O.M. Woestenburg, B.J.M. Frederiks e.a., Tweede evaluatie Wdkb, Den Haag: ZonMW 2019, p. 52 en p. 176. 